\title{
The effect of proatherogenic pathogens on adipose tissue transcriptome and fatty acid distribution in apolipoprotein E-deficient mice
}

\author{
Kati Hyvärinen ${ }^{1 *}$, Anita M Tuomainen', Saara Laitinen², Georg Alfthan, Irma Salminen³, Maija Leinonen ${ }^{4}$, \\ Pekka Saikku ${ }^{5}$, Petri T Kovanen ${ }^{6}$, Matti Jauhiainen ${ }^{3,7}$ and Pirkko J Pussinen ${ }^{1}$
}

\begin{abstract}
Background: Chronic infections have been demonstrated to maintain low-grade systemic inflammation and associate with atherosclerosis. We studied the inflammation- and lipid homeostasis-related effects of Aggregatibacter actinomycetemcomitans ( $\mathrm{Aa}$ ) and Chlamydia pneumoniae (Cpn) infections on the epididymal and inguinal adipose tissue (AT) transcriptomes and fatty acid distribution in apolipoprotein (apo) E-deficient mice. Chow-fed apoE-deficient mice were exposed to 1) chronic intranasal infection with C. pneumoniae (Cpn group), 2) recurrent intravenous infection with A. actinomycetemcomitans (Aa group), 3) a combination of both types of infection (Cpn + Aa group), or 4) infection with the vehicle (control group). Epididymal and inguinal AT gene expression was analyzed using an Illumina Mouse WG-6 v2.0 platform and quantitative PCR (QPCR). Microarray data were analyzed using Gene Ontology enrichment analysis. AT fatty acid analysis was performed using gas-liquid chromatography.

Results: The transcriptomics data revealed significant enrichment in inflammation-associated biological pathways in both AT depots derived from the Aa and Cpn + Aa treated mice compared with the control group. The proportion of saturated fatty acids was higher in the inguinal AT in $A a(p=0.027)$ and $C p n+A a(p=0.009)$ groups and in the epididymal AT in Aa group $(p=0.003)$. The proportion of polyunsaturated fatty acids was significantly lower among all Aa-infected groups in both depots. Chronic Cpn infection displayed only minor effects on transcriptomics and fatty acids of the AT depots.
\end{abstract}

Conclusions: Systemic infection with A. actinomycetemcomitans activates inflammation-related biological pathways and modulates cellular lipid homeostasis. The adverse changes in adipose tissues during chronic infection may promote atherosclerosis.

Keywords: A. actinomycetemcomitans, C. pneumoniae, Adipose tissue, apoE-deficient mice, Transcriptome, Fatty acid distribution

\section{Background}

Atherosclerosis is an inflammatory disease with complex multifactorial pathophysiology. In addition to the chronic inflammation in the vessel wall causing vascular endothelial dysfunction, the progression of the disease may be enhanced by persistent systemic infection, lowgrade inflammation, and metabolic disturbances of major organs such as liver and adipose tissue (AT).

\footnotetext{
* Correspondence: kati.hyvarinen@helsinki.fi

${ }^{1}$ Institute of Dentistry, University of Helsinki, P.O. Box 63, 00014 Helsinki, Finland

Full list of author information is available at the end of the article
}

AT is a multi-functional metabolic organ composed of a heterogeneous cell population. By storing and releasing fatty acids and secreting several important adipokines, AT plays a significant role in both energy metabolism and homeostatic regulation of the endocrine system. The AT dysfunction, followed by the spill-over of free fatty acids (FFAs) into the circulation via enhanced lipolysis and dysregulated expression of adipokines, modifies immune responses and contributes to metabolic disorders such as metabolic syndrome and type 2 diabetes [1,2].

AT depots are dispersed throughout the body and are closely associated with several organs [3]. Recent studies

\section{() Biomed Central}


have reported many site-specific physiological characteristics in AT depots, i.e. differences in cell populations, microvasculature, innervation, and regional variation in metabolic functions including adipokine profiles, lipase activities, uptake of fatty acids, and the insulin response [4]. These differences have a major impact on the proinflammatory potential of the various AT depots.

In humans, visceral AT has been shown to generate angiotensin, interleukin (IL) -6 , and plasminogen activator inhibitor (PAI)-1 at higher levels and leptin and adiponectin at lower levels than subcutaneous AT [5]. Differences in hormone-sensitive lipase activity and maximum lipolytic capacity between omental and subcutaneous AT depots have been reported; however, these phenomena seem to be strongly correlated to the adipocyte size and their capacity to expand [6]. In obese humans, perivisceral AT has been reported to contain more saturated fatty acids (SFAs) and monounsaturated fatty acids (MUFAs) than subcutaneous AT [7]. In mice, high-fat feeding results in a continuous increase in adipocyte size both in subcutaneous and visceral fat. Interestingly, large adipocytes contain relatively more stearic acid and oleic acid, and these cells produce more tumour necrosis factor (TNF)- $\alpha$, leptin, angiotensinogen, adipsin, and PAI-1 compared with small adipocytes [8].

Although AT has considerable pro-inflammatory and pro-atherogenic potential, and contributes to systemic innate immune responses, the impact of chronic systemic infections on AT is rarely investigated. Many pathogens related to common chronic infections, such as gastritis, periodontitis, and pulmonary infections, are lipopolysaccharide (LPS) containing Gram-negative species. Although LPS promotes inflammation mainly through its effects on the monocyte/macrophage function, an in vitro study has demonstrated that subcutaneous human adipocytes secrete large quantities of TNF- $\alpha$ when activated by LPS [9]. Szalowska et al. 2011 have shown that LPS activation of human omental fat results in up-regulated expression of inflammation- and angiogenesis-related genes [10].

The periodontal pathogen Aggregatibacter actinomycetemcomitans and the persistent pulmonary infection agent Chlamydia pneumoniae are Gram-negative pathogens and associated with an increased risk for cardiovascular diseases [11-13]. Both pathogens have been found in human atherosclerotic lesions $[11,14]$, accelerate atherosclerosis in mouse model $[15,16]$, and are highly common among general population $[17,18]$. We have recently shown in apolipoprotein $\mathrm{E}$ (apoE)-deficient mouse model that systemic $A$. actinomycetemcomitans and $C$. pneumoniae infections may induce broad range pro-atherogenic effects including alterations in macrophage cholesterol homeostasis, endothelial function [19], and, moreover, in the liver morphology, fatty acid composition, and inflammation marker profile [20].
In the present study, we investigated the effects of systemic recurrent $A$. actinomycetemcomitans and chronic $C$. pneumoniae infections on epididymal and inguinal AT depots in apoE-deficient mice. In addition, combined infection model was used to study the impact of pathogen burden on these depots. ApoE-deficient mice display a proatherogenic plasma lipoprotein profile and they develop atherosclerotic lesions on a chow diet. In addition, due to decreased levels of LPS-neutralizing high-density lipoproteins, apoE-deficient mice show increased susceptibility to LPS-mediated inflammation compared to wildtype mice [21]. In order to include both visceral and subcutaneous AT and to identify their putative depot-specific pro-inflammatory and pro-atherogenic potential, we utilized both epididymal and inguinal AT depots. We focused on molecules associated with inflammation and lipid homeostasis, which were investigated on the level of gene expression and cellular fat composition.

\section{Methods \\ Mice}

Male apolipoprotein (apo) E-deficient mice (B6.129P2Apoe $^{\text {tm1 Unc }} / \mathrm{Crl}$ ) were purchased from Charles River Laboratories. The mice were fed regular mouse chow $a b$ libitum and maintained in a germ-free environment at the National Public Health Institute Animal Facilities (Helsinki, Finland). Animal care and experimentation were conducted under Animal Care and Use Committee of National Public Health Institute ethical authorization and were in accordance with the guidelines of the Council of Europe.

\section{Bacterial cultures, infection procedure, and serum analyses}

The bacteria cultures and experimental design have been previously reported [20]. Briefly, the clinical $A$. actinomycetemcomitans strain AT445b (serotype b) was cultivated in a tryptic soy-serum-bacitracin-vancomycin medium at $37^{\circ} \mathrm{C}$ with $5 \% \mathrm{CO}_{2}$ for $48 \mathrm{~h}$. The $\mathrm{C}$. pneumoniae isolate, Kajaani 7, a Finnish epidemic strain, was isolated and cultured as previously described [22].

The infection procedure is presented in Table 1 . The experimental design included chronic C. pneumoniae infection model, which was achieved by three consecutive inoculations, recurrent $A$. actinomycetemcomitans infection model mimicking repeated systemic exposure to the pathogen, and a combination of these two infection models to imitate the effects of infection burden. Chronic $C$. pneumoniae infection was induced in younger mice e in order to see the potential effect of persistence. Viable C. pneumoniae (Cpn) was administered intranasally as $2 \times 10^{6}$ inclusion forming units in $40 \mu \mathrm{l}$ of sucrosephosphate-glutamic acid buffer (SPG), and viable $A$. actinomycetemcomitans (Aa) was administered intravenously (via the tail vein) as $1 \times 10^{7}$ colony forming 
Table 1 Experimental design of the study

\begin{tabular}{|c|c|c|c|c|c|c|c|c|c|c|c|c|c|c|c|c|}
\hline \multirow[t]{2}{*}{ Study group } & \multicolumn{16}{|c|}{ Age (weeks) } \\
\hline & 9 & 10 & 11 & 12 & 13 & 14 & 15 & 16 & 17 & 18 & 19 & 20 & 21 & 22 & 23 & 24 \\
\hline Cpn group & $\cdot$ & & $\cdot$ & & $\cdot$ & & & & & & & & & & & + \\
\hline Aa group & & & & & & $\bullet$ & $\bullet$ & $\bullet$ & $\bullet$ & $\bullet$ & $\bullet$ & $\bullet$ & $\bullet$ & $\bullet$ & $\bullet$ & t \\
\hline Cpn + Aa group & $\cdot$ & & $\cdot$ & & $\cdot$ & $\bullet$ & $\bullet$ & $\bullet$ & $\bullet$ & $\bullet$ & $\bullet$ & $\bullet$ & $\bullet$ & $\bullet$ & $\bullet$ & † \\
\hline Control & $\square$ & & $\square$ & & $\square$ & $\circ$ & $\circ$ & $\circ$ & $\circ$ & $\circ$ & $\circ$ & $\circ$ & $\circ$ & $\circ$ & $\circ$ & t \\
\hline
\end{tabular}

The black squares represent $\mathrm{Cpn}$ inoculations and the black circles Aa inoculations. The controls received the respective vehicle (white squares and circles). + , sacrifice; Aa, A. actinomycetemcomitans; Cpn, C. pneumoniae.

units in $50 \mu \mathrm{l}$ of $0.9 \% \mathrm{NaCl}$. The 10 -week experiment included four groups: 1) recurrent Aa infection group (Aa group, $\mathrm{n}=10$ ) with ten Aa inoculations; 2) the chronic Cpn infection group (Cpn group, $\mathrm{n}=10$ ) with three Cpn inoculations; 3) the combined chronic $\mathrm{Cpn}$ and recurrent Aa infection group ( $\mathrm{Cpn}+\mathrm{Aa}$ group, $\mathrm{n}=10)$ with three Cpn inoculations and ten Aa inoculations; and 4) the control group $(n=9)$ with three SPG inoculations and ten $0.9 \% \mathrm{NaCl}$ inoculations.

The serum levels of nonesterified fatty acids (Waco Chemicals $\mathrm{GmbH}$ ), the LPS activity (HyCult biotechnology b.v.), and the serum levels of TNF (Pierce Biotechnology, Inc.) were measured as described in our previous publications $[19,20]$.

\section{Preparation of adipose tissues}

Inguinal and epididymal AT depots were carefully dissected from sacrificed animals. The tissue specimens were stabilized with RNAlater ${ }^{\mathrm{TM}}$ (Sigma) or snap-frozen in liquid nitrogen. All the samples were stored at $-70^{\circ} \mathrm{C}$.

\section{Isolation and quality evaluation of RNA}

Epididymal and inguinal AT homogenization was performed with a Mixer Mill MM 301 (Retsch $\mathrm{GmbH}$ ) and total RNA was extracted using the RNeasy Lipid Tissue Mini Kit (Qiagen). DNase treatment was performed on a column using the RNase-Free DNase Set (Qiagen) and again after RNA extraction using the DNA-free ${ }^{\mathrm{TM}}$ Kit (Ambion). The RNA concentration was determined using a NanoDrop 1000 spectrophotometer (Thermo Scientific). The quality of total RNA was assessed by an Agilent 2100 Bioanalyzer using the Eukaryote Total RNA Nano Kit (Agilent Technologies).

\section{Adipose tissue RNA microarray processing}

Inguinal and epididymal AT gene expression was analyzed using the Illumina Mouse WG-6 v2.0 platform. Three biological replicates were used and the high quality total RNA (RNA integrity number 28.5 ) was amplified using the Illumina TotalPrep RNA Amplification Kit according to the manufacturer's instructions. Briefly, the total RNA was reverse-transcribed using T7 Oligo(dT) primers following the second strand cDNA synthesis.
After purification, the cDNA was in vitro transcripted into cRNA using biotin-labeled nucleoside triphosphates. The quality of biotinylated cRNA was assessed by an Agilent 2100 Bioanalyzer and $1.5 \mu \mathrm{g}$ of cRNA from each sample was hybridized at $58^{\circ} \mathrm{C}$ overnight using the Illumina Whole-Genome Gene Expression Direct Hybridization Assay system with the six-sample BeadChip platform. The signal was developed using streptavidin-Cy3 and the BeadChips were scanned with an Illumina BeadArray Reader.

\section{Microarray data analyses}

The microarray data has been deposited in MIAMEcompliant format in Gene Expression Omnibus (http:// www.ncbi.nlm.nih.gov/geo/), accession number GSE50647. Gene ontology (GO) enrichment analysis for microarray data was performed using the Fisher's exact test, where the observed frequency of each present GO term was compared with the frequency in a reference gene set (control mice). P-values were corrected for multiple hypotheses using the Benjamini-Hochberg false discovery rate [23]. The analyses were performed using the $\mathrm{R}$ Base Package version 2.15.0. The maximum of 20 most enriched GO terms were reported for both epididymal and inguinal AT and ranked according to the p-value. To limit the data and focus on the biologically meaningful pathways and molecular functions, GO terms referring to cellular components were excluded. The fold-change (FC) limitation for the presented up- and down-regulated genes was 2.0 except when observing de novo lipogenesis-associated genes where all results are present.

\section{Quantitative real-time PCR}

Epididymal and inguinal AT cDNA was synthesized from total RNA using the ImProm- $\mathrm{II}^{\mathrm{rs}}$ Reverse Transcription system (Promega). The amount of total RNA in each reverse transcription (RT) reaction was $240 \mathrm{ng}$ for the inguinal AT and $500 \mathrm{ng}$ for the epididymal AT. The number of mice in each group was 10, except for the control group where 9 mice were used. Primers (Thermo Scientific) were designed using Beacon Designer (Premier Biosoft International) and National Center for Biotechnology Information PrimerBLAST (http://www.ncbi.nlm.nih.gov/tools/primer-blast/) 
for CD68, glyceraldehyde-3-phosphate dehydrogenase (Gapdh), monocyte chemoattractant protein 1 (Mcp-1), macrophage migration inhibitory factor (Mif), mannose receptor C type 1 (Mrc-1), myeloperoxidase (Mpo), and secretory leukocyte peptidase inhibitor (Slpi). Primer sequences are presented in Additional file 1: Table S1. Quantitative real-time PCR (QPCR) was performed using the Mx3005 Real-Time QPCR System (Stratagene). The analyses were conducted in $12.5 \mu \mathrm{l}$ reaction mixtures, each containing $2 \mu \mathrm{l}$ of 1:50 dilution of cDNA synthesized in RT reaction, $6.25 \mu \mathrm{l}$ of Brilliant SYBR ${ }^{\circ}$ Green QPCR Master Mix (Stratagene), $30 \mathrm{nM}$ of ROX reference dye (Stratagene), and optimized concentrations of primers (100 nM, except $200 \mathrm{nM}$ for Gapdh). The amplifications were performed using the following thermocycling program: initial denaturation at $95^{\circ} \mathrm{C}$ for $15 \mathrm{~min}, 40$ cycles of $15 \mathrm{~s}$ at $95^{\circ} \mathrm{C}$ and $1 \mathrm{~min}$ at $60^{\circ} \mathrm{C}$ followed by melting curve analysis for $1 \mathrm{~min}$ at $95^{\circ} \mathrm{C}$, gradual decrease to $55^{\circ} \mathrm{C}, 30 \mathrm{~s}$ at $55^{\circ} \mathrm{C}$, gradual increase to $95^{\circ} \mathrm{C}$, and $30 \mathrm{~s}$ at $95^{\circ} \mathrm{C}$. All samples were analyzed as duplicates and the accepted intra-assay coefficient of variation for threshold cycle was $\leq 2.1 \%$. The results were analyzed using Mx3005 Real-Time QPCR System (Stratagene) software and expressed as a $\log _{2}$ fold change $\left(\log _{2} \mathrm{FC}\right)$ to the respective control mice (level set to zero in the analysis). Gapdh was used as a normalization gene and the software utilizes modified comparative quantitation method introduced by Pfaffl (2001) [24].

\section{Adipose tissue fatty acid analysis}

Total lipids were extracted from $30-80 \mathrm{mg}$ of epididymal and inguinal adipose tissue with hexane-isopropanol (3:2) [25] and trans-methylated by heating with acidic methanol (5\% $\left.\mathrm{H}_{2} \mathrm{SO}_{4}\right)$ [26]. The resulting fatty acid methyl ester compositions were analyzed by gas-liquid partition chromatography using a Hewlett Packard 6890 Gas Chromatograph (ChemStation B.01.03 software) with a DB-225 GC column $(30 \mathrm{~m}$, diameter $0.32 \mathrm{~mm}$, phase layer $0.25 \mu \mathrm{m}$; Agilent Technologies). The samples were split injected with hydrogen as a carrier gas and the temperature program was from $160^{\circ} \mathrm{C}$ to $230^{\circ} \mathrm{C}$. The relative amounts of the methylated fatty acids were expressed as percentages of weight normalized to $100 \%$.

\section{Statistical analyses}

The AT fatty acid data were expressed as mean percentages of weight with standard deviations (SDs). The gene expression data were expressed as $\log _{2}$ fold change $\left(\log _{2} \mathrm{FC}\right)$ medians with interquartile ranges (IQRs). The significance of the differences between the experimental and control mouse groups was assessed using the nonparametric Mann-Whitney $U$ test. Bivariate correlations were determined using the Spearman test. Analyses were performed using PASW Statistics 18 (Statistical Package for the Social Sciences).

\section{Results}

Infection-enriched biological pathways in the inguinal AT Infection-enriched biological pathways (i.e., GO terms) and the associated up- and down-regulated genes in the inguinal AT transcriptome are presented in Tables 2, 3 and 4. Compared with the control mice, the expression of "Protein binding" pathway (GO:0005515) was increased ( $\mathrm{p}<0.001)$ most significantly in Aa group (Table 2). In addition, the inflammation-related "Antigen binding" (GO:0003823, $\mathrm{p}=0.009$ ), "Antibacterial humoral response" (GO:0019731, $\mathrm{p}=0.009$ ), and "Antimicrobial humoral response" (GO:0019730, $\mathrm{p}=0.009)$ pathways were significantly enriched (Table 2).

Compared with the control mice, most of the enriched $\mathrm{GO}$ terms in the inguinal AT transcriptome of Cpn group were pathways associated with development- and morphogenesis (Table 3). The most affected pathway was "Negative regulation of cellular process" pathway (GO:0048523, $\mathrm{p}=0.036$ ).

The most significantly enriched pathway in the inguinal AT transcriptome of $\mathrm{Cpn}+\mathrm{Aa}$ group was "Protein binding" (GO:0005515, p <0.001) followed by inflammation-related "Antigen binding" (GO:0003823, $\mathrm{p}<0.001$ ), "Antibacterial humoral response" (GO:0019731, $\mathrm{p}=0.002$ ), and "Antimicrobial humoral response" (GO:0019730, $\mathrm{p}=0.002$ ) pathways (Table 4). Lipid homeostasis-related "Regulation of lipoprotein lipid oxidation" (GO:0060587, $\mathrm{p}=0.046)$ and "Lipoprotein lipid oxidation" (GO:0034439, $\mathrm{p}=0.046$ ) pathways were also enriched.

Infection-enriched biological pathways in the epididymal AT Table 5 presents the Aa infection-enriched biological pathways in the epididymal AT transcriptome. Compared with the control mice, in the epididymal AT, infection enriched the following humoral antibody response and inflammation-associated pathways: "Antigen binding" (GO:0003823, p <0.001), "Antibacterial humoral response" (GO:0019731, p = 0.002), "Antimicrobial humoral response" (GO:0019730, $\mathrm{p}=0.002)$, "Immunoglobulin mediated immune response” (GO:0016064, $\mathrm{p}=0.004$ ), "Humoral immune response mediated by circulating immunoglobulin" (GO:0002455, p = 0.013), and "Inflammatory response" (GO:0006954, $\mathrm{p}=0.049)$. The lipid homeostasis-related "Monocarboxylic acid metabolic process" (GO:0032787, $\mathrm{p}=0.006$ ), "Fatty acid biosynthetic process" (GO:0006633, p =0.006), "Regulation of lipid metabolic process" (GO:0019216, $\mathrm{p}=0.012$ ), "Negative regulation of lipid metabolic process" (GO:0045833, p = 0.015), "Triglyceride metabolic process" (GO:0006641, $\mathrm{p}=$ 0.027 ), and "Regulation of lipid biosynthetic process" (GO:0046890, $\mathrm{p}=0.032$ ) were also enriched.

Table 6 presents the Cpn infection-enriched pathways in the epididymal AT transcriptome. The enriched pathways included "Very long-chain fatty acid metabolic 
Table 2 A. actinomycetemcomitans infection-enriched GO terms in the inguinal AT transcriptome

\begin{tabular}{|c|c|c|c|c|}
\hline \multirow[t]{2}{*}{ GO category } & \multirow{2}{*}{$\begin{array}{l}\text { Enriched } \\
\text { GO term }\end{array}$} & \multirow{2}{*}{$\begin{array}{l}\text { GO term } \\
\text { p-value }\end{array}$} & \multicolumn{2}{|c|}{ GO term-associated gene products } \\
\hline & & & Up-regulated $^{b}$ & Down-regulated $^{\mathbf{b}}$ \\
\hline GO:0005515 & Protein binding & $<0.001$ & $\begin{array}{l}\text { Spon2, S100a8, Ltf, Des, Retnlg, D6Mit97, LOC100047788, Igl, Igh- } \\
\text { V11, Ighg3, Igkv12-46, Igkv5-48, Igkv13-84, Igkv19-93, Igkv15-103 }\end{array}$ & $\begin{array}{c}\text { Zbtb7a, Rhob, Aldh1a1, Ywhag, } \\
\text { Ccdc6, Ptplb, Antxr1, Timp4, Rps3a, } \\
\text { Ddr2, Cidea, Nr1d2, G0s2, Lep, Acta1 }\end{array}$ \\
\hline GO:0019731 & $\begin{array}{l}\text { Antibacterial } \\
\text { humoral } \\
\text { response }\end{array}$ & 0.009 & LOC100047788 & - \\
\hline GO:0019730 & $\begin{array}{l}\text { Antimicrobial } \\
\text { humoral } \\
\text { response }\end{array}$ & 0.009 & LOC100047788 & - \\
\hline GO:0003823 & $\begin{array}{l}\text { Antigen } \\
\text { binding }\end{array}$ & 0.009 & Igkv5-48, LOC100047788 & - \\
\hline
\end{tabular}

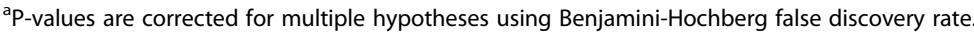

${ }^{b}$ Fold change limit 2.0 .

Number of biological replicates is 3 .

$\mathrm{GO}$, gene ontology. The maximum of $20 \mathrm{GO}$ categories is shown.

process" (GO:0000038, $\mathrm{p}=0.003)$, "Long-chain fatty acid metabolic process" (GO:0001676, $\mathrm{p}=0.003)$, "Long-chain fatty acid-CoA ligase activity" (GO:0004467, p <0.001), and "Very long-chain fatty acid-CoA ligase activity" (GO:0031957, p <0.001) pathways. The most affected pathway was "Defense response" (GO:0006952, $\mathrm{p}=0.003)$.
Table 7 presents the Cpn + Aa infections-enriched pathways in the epididymal AT transcriptome. The "Protein binding" pathway (GO:0005515, p <0.001) included the highest number of affected genes. Inflammation-related "Antigen binding" (GO:0003823, $\mathrm{p}<0.001$ ), "Antibacterial humoral response" (GO:0019731, $\mathrm{p}=0.016)$, and

Table 3 C. pneumoniae infection-enriched GO terms in the inguinal AT transcriptome

\begin{tabular}{|c|c|c|c|c|}
\hline \multirow[t]{2}{*}{ GO category } & \multirow[t]{2}{*}{ Enriched GO term } & \multirow{2}{*}{$\begin{array}{l}\text { GO term } \\
p \text {-value }{ }^{a}\end{array}$} & \multicolumn{2}{|c|}{ GO term-associated gene products } \\
\hline & & & Up-regulated $^{\mathbf{b}}$ & Down-regulated $^{\mathrm{b}}$ \\
\hline GO:0035634 & Response to stilbenoid & $<0.001$ & Ifit3, Usp18 & - \\
\hline GO:0019785 & ISG15-specific protease activity & $<0.001$ & Usp18 & - \\
\hline GO:0032020 & ISG15-protein conjugation & $<0.001$ & Usp18 & - \\
\hline GO:0001823 & Mesonephros development & 0.001 & Osr2, Gpc3 & - \\
\hline GO:0033687 & Osteoblast proliferation & 0.002 & Osr2, Eif2ak2 & - \\
\hline GO:0035116 & Embryonic hindlimb morphogenesis & 0.003 & Osr2, Gpc3 & - \\
\hline GO:2000543 & Positive regulation of gastrulation & 0.008 & Osr2 & - \\
\hline GO:0061029 & Eyelid development in camera-type eye & 0.008 & Osr2 & - \\
\hline GO:0060272 & Embryonic skeletal joint morphogenesis & 0.008 & Osr2 & - \\
\hline GO:0048793 & Pronephros development & 0.008 & Osr2 & - \\
\hline GO:0030282 & Bone mineralization & 0.013 & Osr2, Gpc3 & - \\
\hline GO:0001656 & Metanephros development & 0.013 & Osr2, Gpc3 & - \\
\hline GO:0042474 & Middle ear morphogenesis & 0.020 & Osr2 & - \\
\hline GO:0004221 & Ubiquitin thiolesterase activity & 0.020 & Usp18 & - \\
\hline GO:0035115 & Embryonic forelimb morphogenesis & 0.030 & Osr2 & - \\
\hline GO:0030501 & Positive regulation of bone mineralization & 0.030 & Osr2 & - \\
\hline GO:0048523 & Negative regulation of cellular process & 0.036 & Slfn1, Gpc3, Ppap2b, Eif2ak2, Osr2 & Acaa2, Ddit4 \\
\hline GO:0030163 & Protein catabolic process & 0.042 & Usp18, Gpc3 & - \\
\hline GO:0050678 & Regulation of epithelial cell proliferation & 0.042 & Osr2, Gpc3 & - \\
\hline GO:0043401 & Steroid hormone mediated signaling pathway & 0.042 & - & $\mathrm{Nr} 1 \mathrm{~d} 2$ \\
\hline
\end{tabular}

${ }^{\text {a }}$-values are corrected for multiple hypotheses using Benjamini-Hochberg false discovery rate.

${ }^{\mathrm{b}}$ Fold change limit 2.0.

Number of biological replicates is 3 .

$\mathrm{GO}$, gene ontology. The maximum of $20 \mathrm{GO}$ categories is shown. 


\begin{tabular}{|c|c|c|c|c|}
\hline \multirow[t]{2}{*}{ GO category } & \multirow[t]{2}{*}{ Enriched GO term } & \multirow{2}{*}{$\begin{array}{l}\text { GO term } \\
\text { p-value }{ }^{a}\end{array}$} & \multicolumn{2}{|l|}{ GO term-associated gene products } \\
\hline & & & Up-regulated $^{\mathbf{b}}$ & Down-regulated $^{\mathbf{b}}$ \\
\hline GO:0005515 & Protein binding & $<0.001$ & $\begin{array}{c}\text { lgk-V5, Igkv5-48, Igkv4-80, lgkv8-30, IgkV33, Igkv12-89, Igkv15- } \\
\text { 103, lgkv2-112, D6Mit97, S100a8, Ltf, LOC637260, LOC626347, } \\
\text { Igl, Ighv1-62, Ighv6-3, LOC630305, lghg3, Igh-4,lghg, } \\
\text { LOC100047788, Gm16971, Ngp, Chi3l3 }\end{array}$ & $\begin{array}{l}\text { Aldh1a1, Adh7, Ddx17, } \\
\text { Acta1, Bmp3, Igfbp6, } \\
\text { Tnnc2, Lep, Dpt }\end{array}$ \\
\hline GO:0003823 & Antigen binding & $<0.001$ & LOC100047788, lgkv5-48, lgkv2-112 & - \\
\hline GO:0019731 & $\begin{array}{l}\text { Antibacterial humoral } \\
\text { response }\end{array}$ & 0.002 & LOC100047788 & - \\
\hline GO:0019730 & $\begin{array}{l}\text { Antimicrobial humoral } \\
\text { response }\end{array}$ & 0.002 & LOC100047788 & - \\
\hline GO:0051952 & Regulation of amine transport & 0.002 & - & Lep, Sncg \\
\hline GO:0042572 & Retinol metabolic process & 0.011 & - & Aldh1a1, Adh7 \\
\hline GO:0030534 & Adult behavior & 0.011 & - & Lep, Sncg \\
\hline GO:0014059 & $\begin{array}{l}\text { Regulation of dopamine } \\
\text { secretion }\end{array}$ & 0.011 & - & Sncg \\
\hline GO:0014046 & Dopamine secretion & 0.011 & - & Sncg \\
\hline GO:0006836 & Neurotransmitter transport & 0.011 & - & Slc6a13, Sncg \\
\hline GO:0042573 & $\begin{array}{l}\text { Retinoic acid metabolic } \\
\text { process }\end{array}$ & 0.013 & - & Aldh1a1, Adh7 \\
\hline GO:0002455 & $\begin{array}{l}\text { Humoral immune response } \\
\text { mediated by circulating } \\
\text { immunoglobulin }\end{array}$ & 0.016 & LOC100047788 & - \\
\hline GO:0046928 & $\begin{array}{l}\text { Regulation of } \\
\text { neurotransmitter secretion }\end{array}$ & 0.020 & - & Sncg \\
\hline GO:0008344 & Adult locomotory behavior & 0.042 & - & Sncg \\
\hline GO:0032526 & Response to retinoic acid & 0.044 & - & Aldh1a1, Lep \\
\hline GO:2000366 & $\begin{array}{l}\text { Positive regulation of STAT } \\
\text { protein import into nucleus }\end{array}$ & 0.046 & - & Lep \\
\hline GO:0071298 & $\begin{array}{l}\text { Cellular response to L- } \\
\text { ascorbic acid }\end{array}$ & 0.046 & - & Lep \\
\hline GO:0060587 & $\begin{array}{l}\text { Regulation of lipoprotein lipid } \\
\text { oxidation }\end{array}$ & 0.046 & - & Lep \\
\hline GO:0051956 & $\begin{array}{l}\text { Negative regulation of amino } \\
\text { acid transport }\end{array}$ & 0.046 & - & Lep \\
\hline GO:0034439 & Lipoprotein lipid oxidation & 0.046 & - & Lep \\
\hline
\end{tabular}

aP-values are corrected for multiple hypotheses using Benjamini-Hochberg false discovery rate.

${ }^{\mathrm{b}}$ Fold change limit 2.0.

Number of biological replicates is 3 .

$\mathrm{GO}$, gene ontology. The maximum of $20 \mathrm{GO}$ categories is shown.

"Antimicrobial humoral response" (GO:0019730, p = 0.016) pathways were enriched. There were no enrichments in lipid metabolism-related pathways.

Inflammation- and lipid homeostasis-related up- and down-regulated genes in the inguinal AT

In Aa group, most of the "Protein binding" pathwayassociated up-regulated genes belonged to immunoglobulin variables (Table 2, Additional file 2: Table S2). The most up-regulated genes were S100 calcium binding protein A8 (S100a8, FC =13.27), S100 calcium binding protein A9 (S100a9, FC =9.45), and lactotransferrin $(L t f, \mathrm{FC}=6.62)$.
Lipid homeostasis-associated leptin $(L e p, F C=0.46)$ was down-regulated (Additional file 2: Table S2).

In Cpn group, infection induced down-regulation of acetyl-Coenzyme A acyltransferase 2 (Acaa2, $\mathrm{FC}=$ 0.41), ELOVL family member 6, elongation of long chain fatty acids (Elovl6, FC $=0.44)$, and nuclear receptor subfamily 1 , group D, member $2(N r 1 d 2, \mathrm{FC}=0.44)$ (Additional file 3: Table S3).

In Cpn + Aa group, the majority of up-regulated genes were immunoglobulin variables (Additional file 4: Table $\mathrm{S} 4)$. In addition, S100a9 $(\mathrm{FC}=11.29)$, S100a8 $(\mathrm{FC}=$ 10.96), and $\operatorname{Ltf}(\mathrm{FC}=4.73)$ were up-regulated. Lep $(\mathrm{FC}=$ 
Table 5 A. actinomycetemcomitans infection-enriched GO terms in the epididymal AT transcriptome

\begin{tabular}{|c|c|c|c|c|}
\hline \multirow[t]{2}{*}{ GO category } & \multirow[t]{2}{*}{ Enriched GO term } & \multirow{2}{*}{$\begin{array}{l}\text { Go term } \\
\text { p-value }^{a}\end{array}$} & \multicolumn{2}{|c|}{ GO term-associated gene products } \\
\hline & & & Up-regulated $^{b}$ & Down-regulated $^{\mathbf{b}}$ \\
\hline GO:0003823 & Antigen binding & $<0.001$ & Igk-C, LOC100047788 & - \\
\hline GO:0019731 & Antibacterial humoral response & 0.002 & LOC100047788 & - \\
\hline GO:0019730 & Antimicrobial humoral response & 0.002 & LOC100047788 & - \\
\hline GO:0016064 & Immunoglobulin mediated immune response & 0.004 & LOC100047788 & Bcl6 \\
\hline GO:0032787 & Monocarboxylic acid metabolic process & 0.006 & Pcx, Insig1, Elovl6, Scd2 & - \\
\hline GO:0006633 & Fatty acid biosynthetic process & 0.006 & Insig1, Elovl6, Scd2 & - \\
\hline GO:0019216 & Regulation of lipid metabolic process & 0.012 & Cidea, Insig 1, Thrsp & - \\
\hline GO:0002455 & $\begin{array}{l}\text { Humoral immune response mediated by } \\
\text { circulating immunoglobulin }\end{array}$ & 0.013 & LOC100047788 & - \\
\hline GO:0045833 & Negative regulation of lipid metabolic process & 0.015 & Cidea, Insig1 & - \\
\hline GO:0005515 & Protein binding & 0.022 & $\begin{array}{c}\text { Slc15a2, Cidea, Thrsp, Elovl6, } \\
\text { Lrtm1, lgk-V5, LOC384413, } \\
\text { LOC637227, Insig1, LOC100047162, } \\
\text { LOC669053, Igk-C, LOC100047628, } \\
\text { LOC100047788, lghg, Ighg3, LOC676136 }\end{array}$ & Bcl6, Itga11 \\
\hline GO:0006641 & Triglyceride metabolic process & 0.027 & Thrsp, Insig1 & - \\
\hline GO:0046890 & Regulation of lipid biosynthetic process & 0.032 & Thrsp, Insig1 & - \\
\hline GO:0009611 & Response to wounding & 0.034 & Fabp4, Klf6 & Chst4, Bcl6 \\
\hline GO:0001816 & Cytokine production & 0.045 & Fabp4, Cidea & Bcl6 \\
\hline GO:0001818 & Negative regulation of cytokine production & 0.046 & Cidea & Bcl6 \\
\hline GO:0051973 & Positive regulation of telomerase activity & 0.048 & 9130213B05Rik & - \\
\hline GO:0042938 & Dipeptide transport & 0.048 & Slc15a2 & - \\
\hline GO:0006954 & Inflammatory response & 0.049 & Fabp4 & Chst4, Bcl6 \\
\hline
\end{tabular}

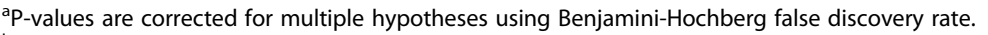

${ }^{\mathrm{b}}$ Fold change limit 2.0.

Number of biological replicates is 3 .

$\mathrm{GO}$, gene ontology. The maximum of $20 \mathrm{GO}$ categories is shown.

$0.46)$ and synuclein $\delta(\mathrm{Sncg}, \mathrm{FC}=0.040)$ were downregulated (Additional file 4: Table S4).

\section{Inflammation- and lipid homeostasis-related up- and} down-regulated genes in the epididymal AT

In Aa group, the enriched "Monocarboxylic acid metabolic process" pathway $(\mathrm{p}=0.006)$ included four up-regulated genes: pyruvate carboxylase $(P c x, \mathrm{FC}=2.82)$, Elovl6 $(\mathrm{FC}=$ $3.21)$, stearoyl-coenzyme A desaturase $2(S c d 2, \mathrm{FC}=2.15)$, and insulin induced gene 1 (Insig1, FC $=2.01$ ) (Additional file 5: Table S5). Insig1, cell death-inducing DNA fragmentation factor, alpha subunit-like effector A (Cidea, FC= 2.53) and thyroid hormone responsive (Thrsp, $\mathrm{FC}=2.26$ ) were associated with the "Regulation of lipid metabolic process" pathway $(\mathrm{p}=0.012)$. In addition, fatty acid binding protein $4(F a b p 4, \mathrm{FC}=2.60)$ and immunoglobulin variables were up-regulated (Additional file 5: Table S5).

In Cpn group, the "Defense response" pathway $(\mathrm{p}=$ 0.003 ) included four defensin subtypes, 5 ' nucleotidase, ecto $(N t 5 e, \mathrm{FC}=3.34)$, and chemokine $(\mathrm{C}-\mathrm{C}$ motif) ligand $8(\mathrm{Ccl} 8, \mathrm{FC}=2.81)$ (Additional file 6: Table S6). The upregulated solute carrier family 27 (fatty acid transporter), member $2(S l c 27 a 2, F C=3.09)$ was associated with the lipid homeostasis-related pathways.

In Cpn + Aa group, a large number of up-regulated genes were immunoglobulin variables and the most upregulated was Ig gamma-2A chain $\mathrm{C}$ region secreted form-like (LOC100047788, FC=37.73) (Additional file 7: Table S7). Lipid homeostasis -associated arachidonate 12lipoxygenase (Alox12, $\mathrm{FC}=3.91)$ was also up-regulated.

The expression of de novo lipogenesis-associated genes Figure 1 presents the expression of de novo lipogenesis associated genes in the AT depot transcriptomes among the different infection models (the data are derived from the microarray experiment). In the epididymal transcriptome of Aa-infected mice, the up-regulated genes were $P c x(\mathrm{FC}=2.82)$, fatty acid synthase $(F a s n, F C=1.81)$, Scd2 $(\mathrm{FC}=2.15)$, and Elovl6 $(\mathrm{FC}=3.21)$ (Figure 1A). Fasn and Elovl6 were down-regulated in the Cpn group in both AT depots (inguinal Fasn FC $=-2.19$, epididymal Fasn $\mathrm{FC}=-2.86$; inguinal Elovl6 $\mathrm{FC}=-2.26$, epididymal Elovl6 FC $=-1.98$ ) (Figure 1B). The combined infection 
Table 6 C. pneumoniae infection-enriched GO terms in the epididymal AT transcriptome

\begin{tabular}{|c|c|c|c|c|}
\hline \multirow[t]{2}{*}{ GO category } & \multirow[t]{2}{*}{ Enriched GO term } & \multirow{2}{*}{$\begin{array}{l}\text { Go term } \\
\text { p-value }\end{array}$} & \multicolumn{2}{|c|}{ GO term-associated gene products } \\
\hline & & & Up-regulated $^{\mathbf{b}}$ & Down-regulated $^{\mathbf{b}}$ \\
\hline GO:0009206 & $\begin{array}{l}\text { Purine ribonucleoside triphosphate } \\
\text { biosynthetic process }\end{array}$ & $<0.001$ & Nme7, Atp1b1, Ldhc,1600029|14Rik & - \\
\hline GO:0006754 & ATP biosynthetic process & $<0.001$ & Nme7, Atp1b1, Ldhc & - \\
\hline GO:0005391 & Sodium:potassium-exchanging ATPase activity & $<0.001$ & Nme7, Atp1b1 & - \\
\hline GO:0031957 & Very long-chain fatty acid-CoA ligase activity & $<0.001$ & Acsbg1, SIc27a2 & - \\
\hline GO:0030317 & Sperm motility & $<0.001$ & Spag6, Tnp1, Ldhc, Smcp & - \\
\hline GO:0004467 & Long-chain fatty acid-CoA ligase activity & $<0.001$ & Acsbg1, Slc27a2 & - \\
\hline GO:0006952 & Defense response & 0.003 & $\begin{array}{l}\text { Ccl8, Arg2, Defb22, Cx3cl1, } \\
\text { Nt5e, Defb29, Defb36, } \\
\text { Defb38, Cfi, Elf3 }\end{array}$ & $\begin{array}{l}\text { Ccl5, Orm1, Orm2, S100a8, } \\
\text { Ccl11 }\end{array}$ \\
\hline GO:0001676 & Long-chain fatty acid metabolic process & 0.003 & Acsbg1, Slc27a2 & - \\
\hline GO:0000038 & Very long-chain fatty acid metabolic process & 0.003 & Acsbg1, Slc27a2 & - \\
\hline GO:0006323 & DNA packaging & 0.004 & Sox9, Prm1 & $\begin{array}{l}\text { Hist1h4i, Hist2h2ac, Hist1h4k, } \\
\text { Hist1h4j, Hist1h3d }\end{array}$ \\
\hline GO:0016338 & Calcium-independent cell-cell adhesion & 0.005 & Cldn2, Cldn11, Cx3cl1 & \\
\hline GO:0009991 & Response to extracellular stimulus & 0.007 & $\begin{array}{l}\text { Slc39a4, Mt3, Srd5a2, } \\
\text { Sox9, Lrp2, Sfrp1, } \\
\text { Arg2, Avpr1a }\end{array}$ & Tnfrsf1 1b, Ccl5, Acta1 \\
\hline GO:0034728 & Nucleosome organization & 0.008 & Sox9, Tnp1 & $\begin{array}{c}\text { Hist1h3d, Hist2h2ac, Hist1h4i, } \\
\text { Hist1h4k, Hist1h4j }\end{array}$ \\
\hline GO:0071345 & Cellular response to cytokine stimulus & 0.008 & $\begin{array}{l}\text { Mt3, Cx3cl1, Krt18, Sox9, } \\
\text { Krt8, Sfrp1, Arg2 }\end{array}$ & $\mathrm{Ccl} 5$ \\
\hline GO:0042493 & Response to drug & 0.008 & $\begin{array}{l}\text { Slc15a2, Mt3, Srd5a2, } \\
\text { Lrp2, Sfrp1, Arg2, Slc22a1 }\end{array}$ & Tnfrsf1 1b, Ccl5, Cox8b \\
\hline GO:0048245 & Eosinophil chemotaxis & 0.009 & LOC100048554 & $\mathrm{Ccl} 5, \mathrm{Ccl} 11$ \\
\hline GO:0022414 & Reproductive process & 0.009 & $\begin{array}{l}\text { Spag6, Sox9, 4931407G18Rik, } \\
\text { Avpr1a, Arg2, Prm1, Tnp1, } \\
\text { Odf2, Smcp, Acsbg1, Cldn11, } \\
\text { Srd5a2, Mycbpap, Sfrp1 }\end{array}$ & $\mathrm{Ccl} 5$ \\
\hline GO:0006333 & Chromatin assembly or disassembly & 0.009 & Sox9, Tnp1 & $\begin{array}{l}\text { Hist1h3d, Hist2h2ac, Hist1h4i, } \\
\text { Hist1h4k, Hist1h4j, }\end{array}$ \\
\hline GO:0048609 & Multicellular organismal reproductive process & 0.010 & $\begin{array}{c}\text { 4931407G18Rik, Avpr1a, } \\
\text { Arg2, Prm1, Spag6, Smcp, } \\
\text { Odf2, Sfrp1, Cldn11, Mycbpap, Sox9, Tnp1 }\end{array}$ & - \\
\hline GO:0032504 & Multicellular organism reproduction & 0.010 & $\begin{array}{c}\text { Sox9, 4931407G18Rik, Arg2, Prm1, } \\
\text { Spag6, Avpr1a, Odf2, Sfrp1, } \\
\text { Cldn11, Tnp1, Mycbpap, Smcp }\end{array}$ & - \\
\hline
\end{tabular}

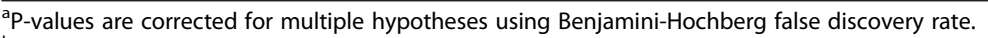

${ }^{\mathrm{b}}$ Fold change limit 2.0 .

Number of biological replicates is 3 .

$\mathrm{GO}$, gene ontology. The maximum of $20 \mathrm{GO}$ categories is shown.

model had little impact on de novo lipogenesis associated gene expression (Figure 1C).

\section{Alterations in QPCR-analyzed mRNA expression levels}

The relative mRNA expression levels of neutrophil activation- (Slpi and $\mathrm{Mpo}$ ) and macrophage phenotype(macrophage type 2 marker $M r c-1)$ and activation- (Mcp1 and Mif) related genes in inguinal and epididymal AT are presented in Table 8 . In the inguinal AT, the relative expression levels of genes encoding Slpi and Mpo were significantly higher in the Aa group (Slpi: $\mathrm{p}=0.003$; Mpo: $\mathrm{p}=0.009$ ) than in control mice (level set to zero in the analysis). Cpn infection did not have a significant effect on the selected gene expression levels.

In the epididymal AT, the relative mRNA expression levels of Mcp-1, Mif, and Slpi in the Aa group, Mrc-1 and CD68 in Cpn group, and Mif in $\mathrm{Aa}+\mathrm{Cpn}$ group were significantly altered but between -1 to $1 \log _{2} \mathrm{FC}$. The Cpn + Aa combination induced a reduction in the $M c p-1$ mRNA levels ( $\mathrm{p}<0.001)$. 
Table 7 Combined chronic C. pneumoniae and recurrent A. actinomycetemcomitans infections-enriched GO terms in the epididymal AT transcriptome

\begin{tabular}{|c|c|c|c|c|}
\hline \multirow{2}{*}{$\begin{array}{l}\text { GO } \\
\text { category }\end{array}$} & \multirow[t]{2}{*}{ Enriched GO term } & \multirow[t]{2}{*}{ Go term $p$-value ${ }^{a}$} & \multicolumn{2}{|c|}{ GO term-associated gene products } \\
\hline & & & Up-regulated $^{\mathbf{b}}$ & Down-regulated $^{\mathbf{b}}$ \\
\hline GO:0045653 & $\begin{array}{l}\text { Negative regulation of } \\
\text { megakaryocyte } \\
\text { differentiation }\end{array}$ & $<0.001$ & - & $\begin{array}{l}\text { Hist1h4h, Hist1h4i, Hist1h4k, } \\
\text { Hist1h4j }\end{array}$ \\
\hline GO:0006334 & Nucleosome assembly & $<0.001$ & Sox9 & $\begin{array}{l}\text { Hist1h4j, Hist1h4i, Hist1h4k, } \\
\text { Hist1h4h, Hist1h3d, Hist2h2ac }\end{array}$ \\
\hline GO:0005515 & Protein binding & $<0.001$ & $\begin{array}{l}\text { BC021891, Lrrc48, Gja1, Cldn2, Lrtm1, Pcp4l1, Cldn11, } \\
\text { Ubd, Dynlrb2, Mt3, Clic6, Sh3gl2, Lrp2, Nme7, Slc40a1, } \\
\text { Cxcl13, Fcgr4, Spag6, Ccl8, Sox9, Alox12, Sfrp1, Ighv1-62, } \\
\text { Col6a5, C7, Ighg3, Ighg, LOC100047788, Igk-C, D6Mit97, } \\
\text { Igk-V5, lgkv12-46, LOC384419, LOC637227, Igkv4-68 }\end{array}$ & $\begin{array}{l}\text { Itga11, Acta1, Bmp3, Sfrp5, } \\
\text { Hist1h4i, Hist1h4h, Hist1h4k, } \\
\text { Wdr92, Hist1h3d, Hist1h4j }\end{array}$ \\
\hline GO:0003823 & Antigen binding & $<0.001$ & LOC100047788, lgk-C & - \\
\hline GO:0016337 & Cell-cell adhesion & 0.004 & Sox9, Cxcl13, Cldn11, 1110049B09Rik, Cldn2, Dsg2 & Chst4 \\
\hline GO:0016338 & $\begin{array}{l}\text { Calcium-independent } \\
\text { cell-cell adhesion }\end{array}$ & 0.011 & Cldn2, Cldn11 & - \\
\hline GO:2000117 & $\begin{array}{l}\text { Negative regulation of } \\
\text { cysteine-type } \\
\text { endopeptidase activity }\end{array}$ & 0.016 & Sfrp1, Mt3 & - \\
\hline GO:0019731 & $\begin{array}{l}\text { Antibacterial humoral } \\
\text { response }\end{array}$ & 0.016 & LOC100047788 & - \\
\hline GO:0019730 & $\begin{array}{l}\text { Antimicrobial humoral } \\
\text { response }\end{array}$ & 0.016 & LOC100047788 & - \\
\hline GO:0008219 & Cell death & 0.016 & $\begin{array}{c}\text { Mt3, Alox12, Sox9, Slc40a1, Sfrp1, Acsbg 1, Mmd2, Ubd, } \\
\text { Bex2, Dsg2, Gja1 }\end{array}$ & Lyz1, Wdr92 \\
\hline GO:0071504 & $\begin{array}{l}\text { Cellular response to } \\
\text { heparin }\end{array}$ & 0.021 & Sfrp1, Sox9 & - \\
\hline GO:0006352 & $\begin{array}{l}\text { Transcription initiation, } \\
\text { DNA-dependent }\end{array}$ & 0.021 & - & $\begin{array}{l}\text { Hist1h4h, Hist1h4i, Hist1h4k, } \\
\text { Hist1h4j }\end{array}$ \\
\hline GO:0019835 & Cytolysis & 0.024 & Mmd2 & Lyz1 \\
\hline GO:0008253 & 5'-nucleotidase activity & 0.041 & $\mathrm{Nt5e}, \mathrm{Acpp}$ & - \\
\hline
\end{tabular}

${ }^{\mathrm{a}} \mathrm{P}$-values are corrected for multiple hypotheses using Benjamini-Hochberg false discovery rate.

${ }^{\mathrm{b}}$ Fold change limit 2.0.

Number of biological replicates is 3 .

$\mathrm{GO}$, gene ontology. The maximum of $20 \mathrm{GO}$ categories is shown.

\section{Changes in AT fatty acid composition}

The proportions of fatty acids in the epididymal and inguinal AT are presented in Figure 2. In the inguinal AT, Aa infection induced a significantly higher proportion of SFAs (Aa group: $\mathrm{p}=0.027$; $\mathrm{Cpn}+\mathrm{Aa}$ group: $\mathrm{p}=0.009$; Figure $2 \mathrm{~A}$ ) and a lower proportion of PUFAs (Aa group: $\mathrm{p}=0.006 ; \mathrm{Cpn}+\mathrm{Aa}$ group: $\mathrm{p}=0.022$; Figure $2 \mathrm{C}$ ) compared to the control mice. The proportion of MUFAs was greater in the Cpn group ( $p=0.018$; Figure $2 B)$.

In the epididymal AT, the proportions of SFAs were higher among all infected mice but the difference reached statistical significance only in the Aa group ( $\mathrm{p}=$ 0.003; Figure 2A). The proportion of PUFAs was significantly lower in the $\mathrm{Aa}(\mathrm{p}=0.005)$ and $\mathrm{Cpn}+\mathrm{Aa}$ groups (0.016) (Figure 2C). When the two AT depots were compared, the proportion of SFAs was lower in the epididymal AT than in the inguinal AT in the control group $(17.1 \pm 1.8$ vs. $20.7 \pm 2.1 \%$ of total FA, respectively; $\mathrm{p}=0.002)$ and the $\mathrm{Aa}+\mathrm{Cpn}$ group $(19.0 \pm 2.3$ vs. $24.2 \pm$ $3.0 \%$ of total FA, respectively; $\mathrm{p}=0.001)$.

\section{Associations between serum and AT parameters}

The associations between different serum and AT variables were determined by correlation analysis (data from all infection models and the controls combined) and presented as graphs in Figure 3. Serum LPS activity correlated positively with the serum FFA concentration $(\mathrm{p}<0.001$, Figure $3 \mathrm{~A})$ and with the proportion of SFA in the epididymal AT $(p=0.030$, Figure $3 B)$, and negatively with both inguinal $(p=0.045$, Figure $3 \mathrm{D})$ and epididymal $(\mathrm{p}=0.013$, Figure $3 \mathrm{C}$ ) proportions of PUFA.

\section{Discussion}

In the present study, we examined the inflammationand lipid homeostasis-related effects of systemic $A$. 


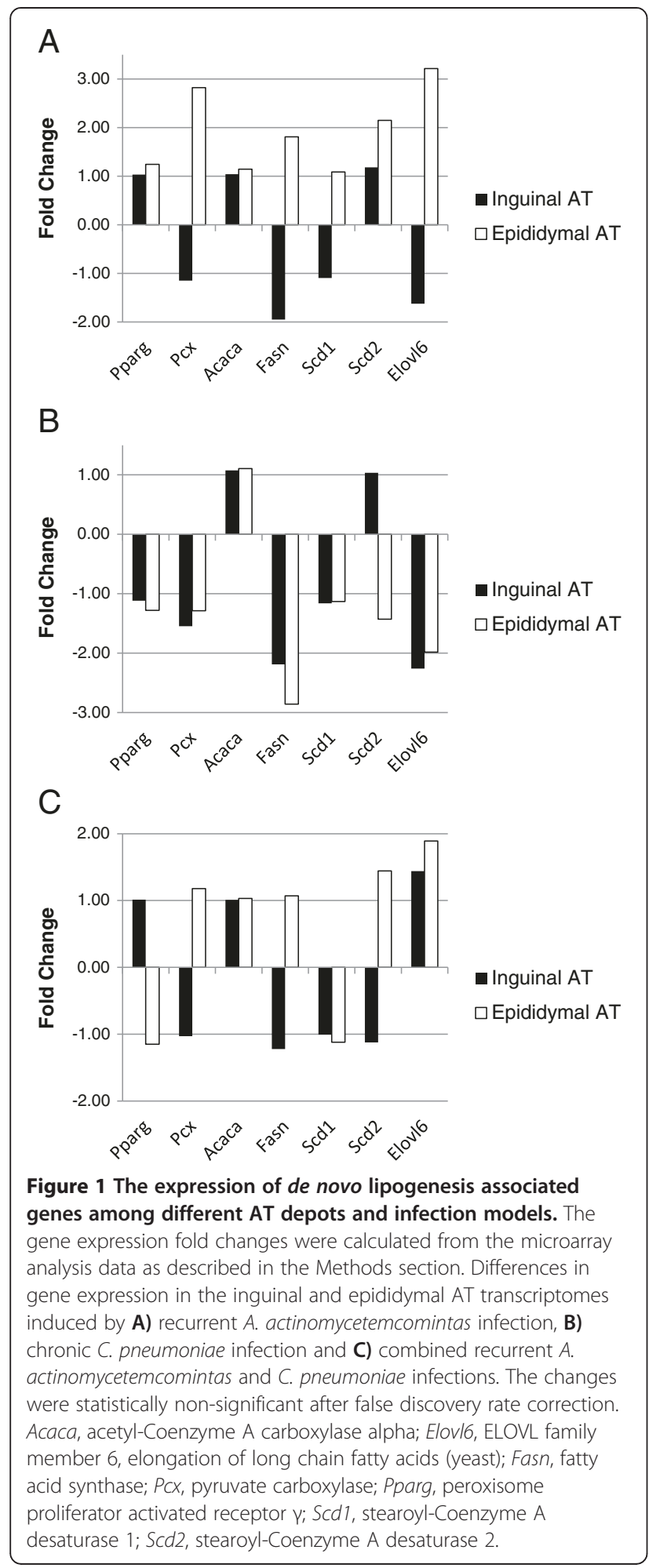

actinomycetemcomitans and C. pneumoniae infections on AT derived from chow-fed apoE-deficient mice. These effects were examined on gene expression and fat composition level in both inguinal and epididymal AT depots. Recurrent Aa infection affected both AT
Table 8 Relative changes in mRNA expression levels of selected genes in inguinal and epididymal AT

\begin{tabular}{|c|c|c|c|c|}
\hline \multirow{3}{*}{ Tissue } & \multirow{3}{*}{ Gene } & $\begin{array}{l}\text { Aa group } \\
(n=10)\end{array}$ & $\begin{array}{l}\text { Cpn group } \\
(n=10)\end{array}$ & $\begin{array}{c}\text { Cpn + Aa group } \\
(n=10)\end{array}$ \\
\hline & & \multicolumn{3}{|c|}{ Median $\log _{2}$ fold change (IQRs) ${ }^{a}$} \\
\hline & & \multicolumn{3}{|c|}{ p-value ${ }^{b}$} \\
\hline \multirow[t]{12}{*}{ Inguinal AT } & $M c p-1$ & $-0.78(1.96)$ & $-0.31(1.44)$ & $-0.53(1.76)$ \\
\hline & & 0.671 & 0.348 & 0.020 \\
\hline & Mrc-1 & $-0.19(1.05)$ & $-0.17(1.00)$ & $0.02(2.08)$ \\
\hline & & 0.671 & 1.000 & 1.000 \\
\hline & CD68 & $0.44(1.56)$ & $0.25(1.23)$ & $0.03(1.36)$ \\
\hline & & 0.203 & 0.061 & 0.437 \\
\hline & Mif & $0.57(2.15)$ & $0.40(1.94)$ & $-0.11(1.67)$ \\
\hline & & 0.203 & 0.348 & 1.000 \\
\hline & Slpi & $4.73(2.99)$ & $-1.18(3.55)$ & $2.79(6.50)$ \\
\hline & & 0.003 & 0.061 & 0.437 \\
\hline & Mpo & $4.30(2.64)$ & $-0.48(3.75)$ & $4.04(7.01)$ \\
\hline & & 0.009 & 0.115 & 0.348 \\
\hline \multirow[t]{10}{*}{ Epididymal AT } & $M c p-1$ & $-0.73(1.97)$ & $-0.41(1.88)$ & $-1.03(1.46)$ \\
\hline & & 0.020 & 0.203 & $<0.001$ \\
\hline & Mrc-1 & $-0.16(0.88)$ & $0.60(0.53)$ & $-0.17(0.99)$ \\
\hline & & 0.437 & 0.003 & 0.599 \\
\hline & $C D 68$ & $-0.39(0.90)$ & $0.58(0.76)$ & $0.55(1.86)$ \\
\hline & & 0.120 & 0.034 & 0.600 \\
\hline & Mif & $-0.88(0.70)$ & $-0.13(1.06)$ & $-0.86(0.67)$ \\
\hline & & 0.020 & 0.203 & $<0.001$ \\
\hline & SIpi & $-0.89(2.11)$ & $0.20(2.20)$ & $-0.24(2.07)$ \\
\hline & & 0.002 & 0.203 & 0.600 \\
\hline
\end{tabular}

${ }^{\mathrm{a} M e d i a n} \mathrm{Log}_{2}$ fold change (IQRs) to the control mice. The control mice have been set into the value of 0 .

${ }^{\mathrm{b}}$ The Mann-Whitney $U$ Test with the control mice as the reference group. Aa group, recurrent $A$. actinomycetemcomitans infection; $C$ pn group, chronic $C$. pneumoniae infection; $\mathrm{Cpn}+\mathrm{Aa}$ group, combined recurrent $A$.

actinomycetemcomitans and chronic $C$. pneumoniae infections; IQR, interquartile range; $M c p-1$, monocyte chemoattractant protein 1; Mif, macrophage migration inhibitory factor, $\mathrm{MrC}-1$, mannose receptor $\mathrm{C}$ type 1; Mpo, myeloperoxidase; Slpi, secretory leukocyte peptidase inhibitor.

depots significantly: inflammation-related biological pathways were enriched in inguinal AT and both inflammation- and lipid homeostasis-related pathways were enriched in epididymal AT. AT fat distribution was altered and SFAs were increased at the expense of PUFAs in both epididymal and inguinal AT among all $A$. actinomycetemcomitans-infected mice. The impact of chronic C. pneumoniae infection on AT depots was less prominent.

The mouse models used in the present study were designed to display chronic infections. Our Aa model is characterized by endotoxemia and systemic inflammation. The observed increased humoral immune responses can be somewhat expected, because we have previously shown that 


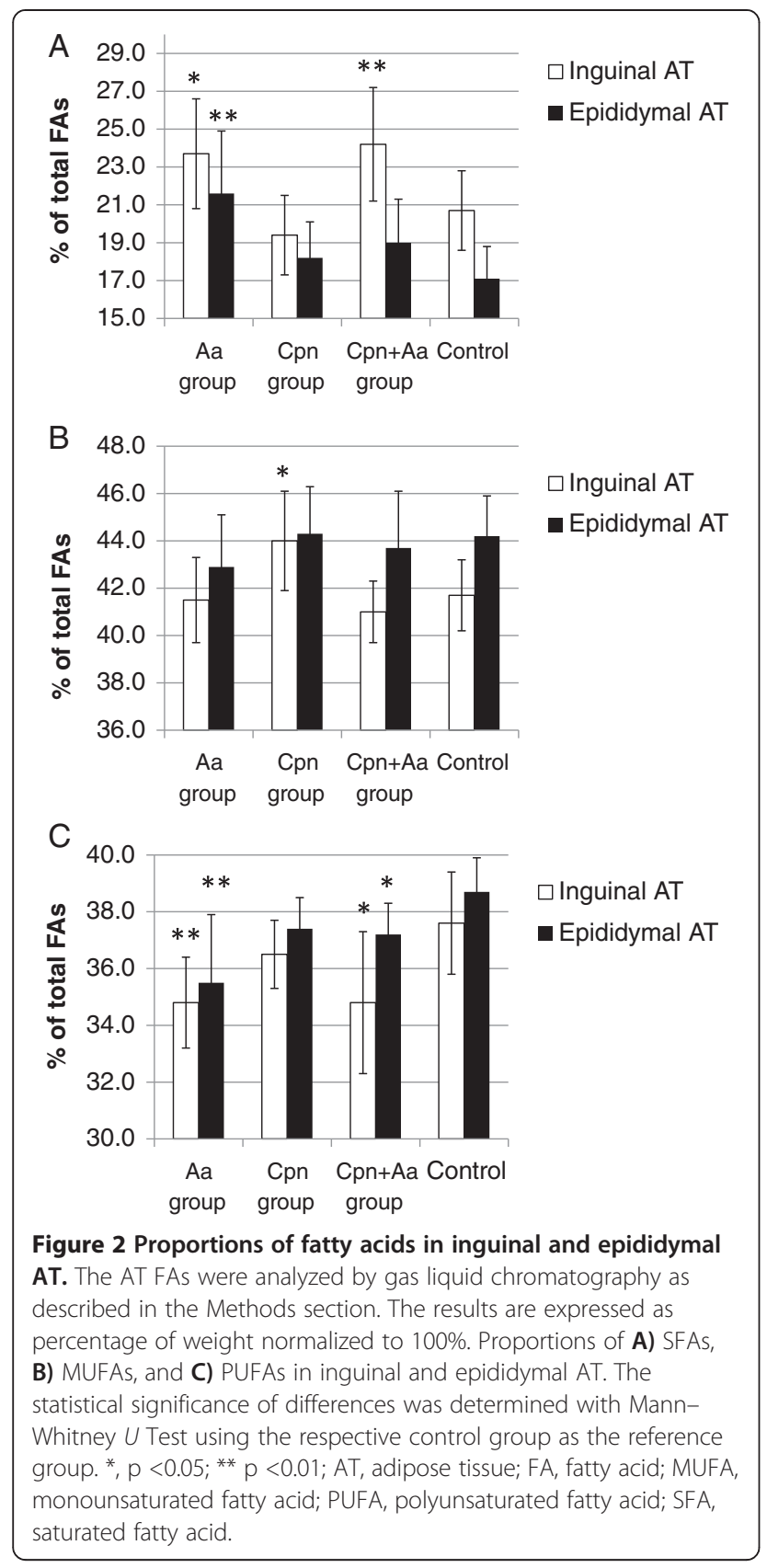

the serum levels of LPS activity, TNF $\alpha$, and IgG antibodies against $A$. actinomycetemcomitans after 10 intravenous injections of live bacteria are significantly higher in the Aa group compared with the control group $[19,20]$. The persistence of C. pneumonia after three inoculations was also shown as the pathogen was recovered from the lungs of the mice [20]. Since atherosclerosis is a multiorgan disease, our aim was to broaden the study from the lipid depots in heart and liver to adipose tissue, which plays an important role in sustaining systemic inflammation and proatherogenic lipid profile.
Experimental acute endotoxemia has been shown to induce general insulin resistance and local and adaptive inflammation in human subcutaneous AT [27]. In our study, Aa infection enriched inflammation-related pathways in the inguinal AT. QPCR analysis verified upregulated expression of Mpo and Slpi, and the most upregulated genes in the microarray analysis were S100a8 and Ltf. These innate immunity-associated gene products are considered anti-inflammatory mediators and they exhibit various antimicrobial functions such as promotion of oxidative activity responses [28-30]. Human Slpi and Ltf have been shown to co-localize in secondary granules and they are co-released after neutrophil activation [31]. Interestingly, increased plasma Slpi levels were associated with progressive metabolic dysfunction in men [32]. Despite the up-regulation in neutrophil activation-related genes, we did not observe changes in the mRNA expression of genes associated with classically or alternatively activated macrophages. The response of Aa infection in the epididymal AT was quite distinct. As in inguinal AT, the humoral antibacterial response and immunoglobulin-related pathways were enriched. However, the myeloid cell-specific signs of enhanced oxidative stress were absent, expression of Slpi was somewhat down-regulated and, instead, several lipid homeostasis-related biological pathways were enriched.

On AT fatty acid level, we observed a potentially adverse increase in the proportion of SFAs among all Aa-infected mice. Mengting et al. 2010 reported that compared with lean mice, obese mice have a higher level of SFAs in their epididymal AT [33]. An interesting study by Suganami et al. 2007 demonstrated that SFAs released by hypertrophied adipocytes activate the NF- $\mathrm{KB}$ pathway in the macrophages with ensuing TNF- $\alpha$ release [34]. The subsequent lipolytic release of SFAs creates a positive feed-back loop between adipocytes and macrophages. Importantly, the macrophagederived TNF- $\alpha$ also resulted in NF-kB-dependent release of proinflammatory cytokines from the adipocytes. Both LPS and SFA have been shown to generate endoplasmic reticulum stress in primary human adipocytes [35]. Elevated levels of SFAs in both epididymal and inguinal AT depots in the Aa and Cpn + Aa groups suggested an increased proinflammatory potential of these AT depots. In addition, because PUFAs have been reported to inhibit the TLR dimerization induced by SFAs [36], the significantly decreased proportion of PUFAs among all $A$. actinomycetemcomitans-infected mice may intensify the effects of increased SFAs. The proportion of PUFAs also showed a significant inverse association with LPS serum activity. This result may be due to LPS-triggered enhanced oxidative stress in the AT, followed by the peroxidation of PUFAs. In addition to intracellular effects, LPS has been shown to elevate the levels of circulating FFAs in rodents in vivo [37]. This association was also found in our study as 


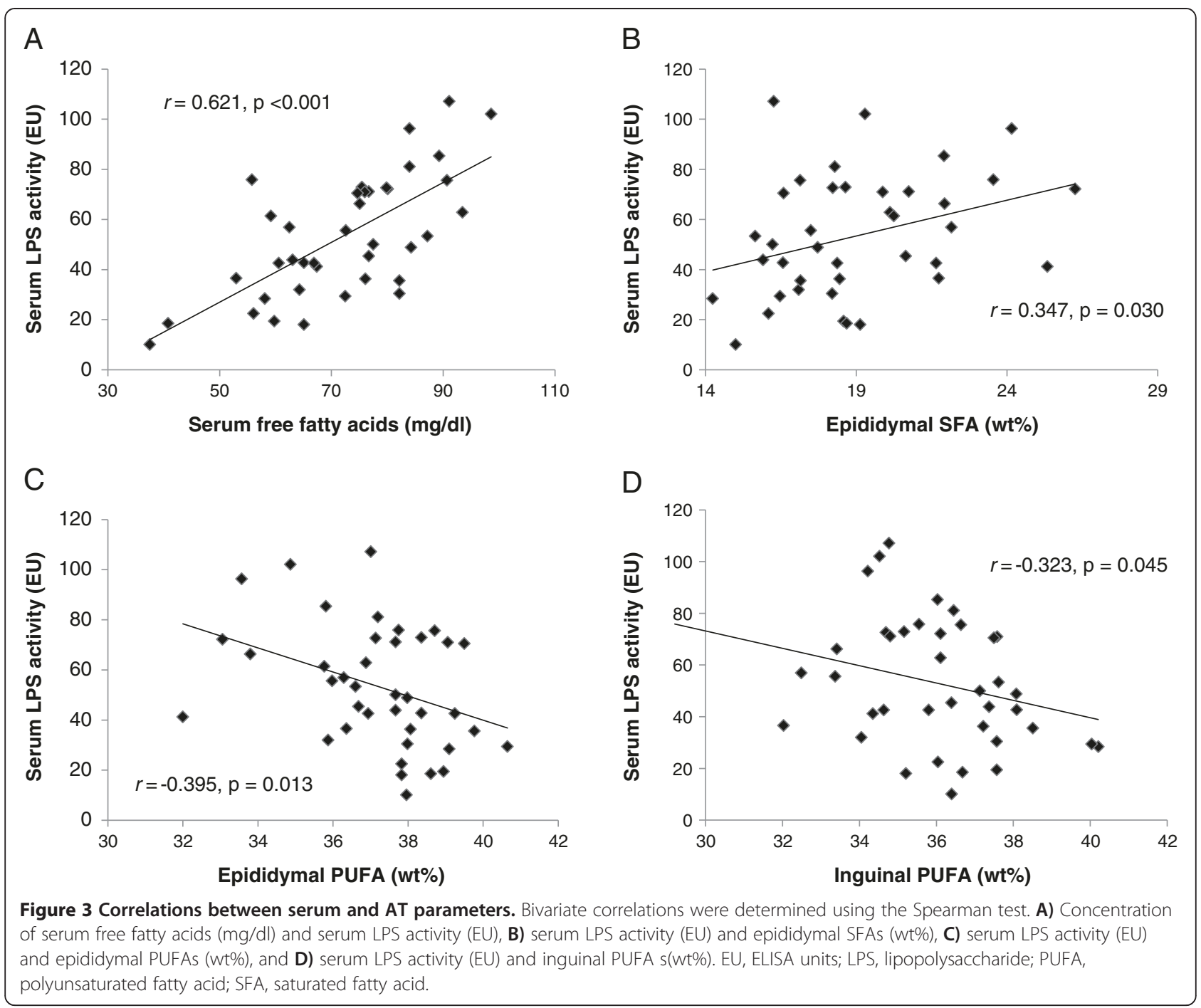

there was a strong positive correlation between serum LPS activity and the FFA level.

Lipid homeostasis-related biological pathways were enriched and four important de novo lipogenesis-related genes were moderately up-regulated in the epididymal AT in Aa group. The observed up-regulation of $P c x$ and Fasn could partially explain the increase in the SFA proportion. However, up-regulation of de novo lipogenesis genes was not observed in Cpn and Cpn + Aa groups, indicating the involvement of other regulatory pathways affecting SFA levels in the AT.

Chronic infection with C. pneumoniae did not enhance the pathways associated with humoral antibody response, and moreover, the effects on the AT depot fatty acid distribution were less evident than with Aa infection. However, the "Defense response" pathway which included four upregulated defensins was enriched in the epididymal AT depot. Previously, C. pneumoniae infection in vitro was reported to induce human $\beta$-defensin 2 production mediated by the TLR4 pathway in monocytes [38]. Although both $C$. pneumoniae and $A$. actinomycetemcomitans are Gram-negative pathogens, the effects of Cpn infection differed considerably from those of Aa infection. This result may be due to the distinct infection routes and $C$. pneumoniae being an obligatory intracellular pathogen. In addition, the difference in the infection time points may also influence the outcome and, altogether, the character of chronic infection differs from the recurrent one. The combined infection model displayed a humoral antibody response and changes in AT depot FA distribution similar to those with single Aa infection. Nevertheless, indicators of the potentially amplified de novo lipogenesis in epididymal AT remained absent.

The major limitation of the study was the small number of mice available for the microarray analysis, which resulted in non-significant gene FC-results after FDR correction. Although the apoE-deficient mouse model has been utilized widely in atherosclerosis research, it 
possesses certain drawbacks, such as a somewhat nonphysiological lipoprotein profile [39]. The adipocytes of apoE-deficient mice are smaller, contain fewer lipids, and accumulate less triglycerides from very low-density lipoproteins and chylomicrons compared with adipocytes derived from wild-type mice [40,41]. In addition, because apoE has been shown to protect against LPSderived sepsis, apoE deficiency actually exposes mice to the deleterious and possibly proatherogenic effects of LPS [21]. Nevertheless, the augmented susceptibility to LPS may produce a more human-like response, because rodents are generally more resistant to LPS-mediated effects than humans. Our study design included only males and therefore we could only draw gender-specific conclusions. It is noteworthy that, in mice, approximately $20 \%$ of AT genes exhibit sexual dimorphism (FC $>1.2$ ), and the enriched functional categories with $\mathrm{FC}>3$ include "Lipid metabolism" [42].

\section{Conclusions}

The present study introduces in vivo evidence that systemic infection of $A$. actinomycetemcomitans activates inflammation-related biological pathways and alters the lipid homeostasis adversely in both inguinal and epididymal AT depots in apoE-deficient mice. The results suggest that repeated endotoxemia promotes AT dysfunction as shown by accumulation of saturated fat in the tissue and spill-over of free fatty acids into the circulation possibly via induced lipolysis. These observations may be useful when studying the potential mechanism linking adipose tissue to the proposed atherogenicity of the chronic infections.

\section{Additional files}

Additional file 1: Table S1. QPCR primer sequences.

Additional file 2: Table S2. Differentially expressed genes in the inguinal AT transcriptome of recurrent A. actinomycetemcomitans-infected mice.

Additional file 3: Table S3. Differentially expressed genes in the inguinal AT transcriptome of chronic C. pneumoniae-infected mice.

Additional file 4: Table S4. Differentially expressed genes in the inguinal AT transcriptome of combined chronic C. pneumoniae and recurrent $A$. actinomycetemcomitans-infected mice.

Additional file 5: Table S5. Differentially expressed genes in the epididymal AT transcriptome of recurrent A. actinomycetemcomitansinfected mice.

Additional file 6: Table S6. Differentially expressed genes in the epididymal AT transcriptome of combined chronic C. pneumoniaeinfected mice.

Additional file 7: Table S7. Differentially expressed genes in the epididymal AT transcriptome of combined chronic C. pneumoniae and recurrent $A$. actinomycetemcomitans-infected mice.

\section{Abbreviations}

Aa: Aggregatibacter actinomycetemcomitans; apoE: apolipoprotein E;

AT: Adipose tissue; Cpn: Chlamydia pneumoniae; FC: Fold change; FDR: False discovery rate; FFA: Free fatty acid; GO: Gene ontology; IQR: Interquartile range; LPS: Lipopolysaccharide; MUFA: Monounsaturated fatty acid; PAI 1: Plasminogen activator inhibitor-1; PUFA: Polyunsaturated fatty acid; QPCR: Quantitative polymerase chain reaction; SD: Standard deviation; SFA: Saturated fatty acid; SPG: Sucrose-phosphate-glutamic acid buffer; TLR: Toll-like receptor; TNF-a: Tumour necrosis factor a.

\section{Competing interests}

The authors declare that they have no competing interests.

\section{Authors' contributions}

KH, AMT, SL, MJ, PTK, ML, PS, GA, and PJP designed the study. KH performed experiments, analyzed and interpreted data, initially drafted the manuscript, and prepared tables and figures. AMT, SL, and IS performed experiments and edited the manuscript. MJ, PTK, ML, PS, GA, and PJP critically revised the manuscript and contributed to discussion. All authors read and approved the final manuscript.

\section{Acknowledgements}

The authors are grateful for the valuable work of Saija Perovuo, Tiina Karvonen, and Pirjo Laaksonen. We also thank the personnel at Biomedicum Genomics (Helsinki, Finland) and Lilli Saarinen at the Computational Systems Biology Laboratory (University of Helsinki, Helsinki, Finland). Wihuri Research Institute is maintained by the Jenny and Antti Wihuri Foundation. This work was supported by the Sigrid Juselius Foundation [to PJP]; the Finnish Denta Society Apollonia [to PJP]; the Paulo Foundation [to PJP]; the Jenny and Antti Wihuri Foundation [to KH, to PJP]; the Aarno Koskelo Foundation [to $\mathrm{KH}$; the Ida Montin Foundation (to KH); the Finnish Atherosclerosis Society (to $\mathrm{KH}$ ); and the Research Council for the Health, Academy of Finland, Grant 132629 (to MJ).

\section{Author details}

'Institute of Dentistry, University of Helsinki, P.O. Box 63, 00014 Helsinki, Finland. ${ }^{2}$ Finnish Red Cross Blood Service, Helsinki, Finland. ${ }^{3}$ National Institute for Health and Welfare, Helsinki, Finland. ${ }^{4}$ National Institute for Health and Welfare, Oulu, Finland. ${ }^{5}$ Department of Medical Microbiology, University of Oulu, Oulu, Finland. ${ }^{6}$ Wihuri Research Institute, Helsinki, Finland. ${ }^{7}$ FIMM, Institute for Molecular Medicine, Helsinki, Finland.

Received: 28 March 2013 Accepted: 4 October 2013

Published: 17 October 2013

\section{References}

1. Lafontan M: Advances in adipose tissue metabolism. Int J Obes (Lond) 2008, 32(Suppl 7):S39-S51.

2. Ouchi N, Parker JL, Lugus JJ, Walsh K: Adipokines in inflammation and metabolic disease. Nat Rev Immunol 2011, 11(2):85-97.

3. Hassan M, Latif N, Yacoub M: Adipose tissue: friend or foe? Nat Rev Cardiol 2012, 9(12):689-702.

4. Lee MJ, Wu Y, Fried SK: Adipose tissue heterogeneity: implication of depot differences in adipose tissue for obesity complications. Mol Aspects Med 2013, 34(1):1-11.

5. Wajchenberg BL, Giannella-Neto D, da Silva ME, Santos RF: Depot-specific hormonal characteristics of subcutaneous and visceral adipose tissue and their relation to the metabolic syndrome. Horm Metab Res 2002, 34(11-12):616-621.

6. Reynisdottir S, Dauzats M, Thorne A, Langin D: Comparison of hormonesensitive lipase activity in visceral and subcutaneous human adipose tissue. J Clin Endocrinol Metab 1997, 82(12):4162-4166.

7. Garaulet M, Perez-Llamas F, Perez-Ayala M, Martinez P, de Medina FS, Tebar FJ, Zamora S: Site-specific differences in the fatty acid composition of abdominal adipose tissue in an obese population from a Mediterranean area: relation with dietary fatty acids, plasma lipid profile, serum insulin, and central obesity. Am J Clin Nutr 2001, 74(5):585-591.

8. Matsubara Y, Kano K, Kondo D, Mugishima H, Matsumoto T: Differences in adipocytokines and fatty acid composition between two adipocyte fractions of small and large cells in high-fat diet-induced obese mice. Ann Nutr Metab 2009, 54(4):258-267.

9. Hoareau L, Bencharif K, Rondeau P, Murumalla R, Ravanan P, Tallet F, Delarue P, Cesari M, Roche R, Festy F: Signaling pathways involved in LPS 
induced TNFalpha production in human adipocytes. J Inflamm (Lond) 2010, 7:1.

10. Szalowska E, Dijkstra M, Elferink MG, Weening D, de Vries M, Bruinenberg M, Hoek A, Roelofsen H, Groothuis GM, Vonk RJ: Comparative analysis of the human hepatic and adipose tissue transcriptomes during LPS-induced inflammation leads to the identification of differential biological pathways and candidate biomarkers. BMC Med Genomics 2011, 4:71.

11. Kalayoglu MV, Libby P, Byrne GL: Chlamydia pneumoniae as an emerging risk factor in cardiovascular disease. JAMA 2002, 288(21):2724-2731.

12. Pussinen PJ, Nyyssönen $K$, Alfthan G, Salonen R, Laukkanen JA, Salonen JT: Serum antibody levels to Actinobacillus actinomycetemcomitans predict the risk for coronary heart disease. Arterioscler Thromb Vasc Biol 2005, 25(4):833-838.

13. Hyvärinen K, Mäntylä P, Buhlin K, Paju S, Nieminen MS, Sinisalo J, Pussinen PJ: A common periodontal pathogen has an adverse association with both acute and stable coronary artery disease. Atherosclerosis 2012, 223(2):478.

14. Kozarov EV, Dorn BR, Shelburne CE, Dunn WA Jr, Progulske-Fox A: Human atherosclerotic plaque contains viable invasive Actinobacillus actinomycetemcomitans and Porphyromonas gingivalis. Arterioscler Thromb Vasc Biol 2005, 25(3):e17-e18

15. Moazed TC, Campbell LA, Rosenfeld ME, Grayston JT, Kuo CC: Chlamydia pneumoniae infection accelerates the progression of atherosclerosis in apolipoprotein E-deficient mice. J Infect Dis 1999, 180(1):238-241.

16. Zhang T, Kurita-Ochiai T, Hashizume T, Du Y, Oguchi S, Yamamoto M: Aggregatibacter actinomycetemcomitans accelerates atherosclerosis with an increase in atherogenic factors in spontaneously hyperlipidemic mice. FEMS Immunol Med Microbiol 2010, 59(2):143.

17. Grayston JT, Campbell LA, Kuo CC, Mordhorst CH, Saikku P, Thom DH, Wang SP: A new respiratory tract pathogen: Chlamydia pneumoniae strain TWAR. J Infect Dis 1990, 161(4):618-625.

18. Könönen E, Paju S, Pussinen PJ, Hyvönen M, Di Tella P, Suominen-Taipale L, Knuuttila M: Population-based study of salivary carriage of periodontal pathogens in adults. J Clin Microbiol 2007, 45(8):2446-2451.

19. Tuomainen AM, Hyvärinen $\mathrm{K}$, Ehlers $\mathrm{Pl}$, Mervaala E, Leinonen M, Saikku $\mathrm{P}$, Kovanen PT, Jauhiainen M, Pussinen PJ: The effect of proatherogenic microbes on macrophage cholesterol homeostasis in apoE-deficient mice. Microb Pathog 2011, 51(3):217-224.

20. Hyvärinen $K$, Tuomainen AM, Laitinen S, Bykov IL, Törmäkangas L, Lindros $K$, Käkelä R, Alfthan G, Salminen I, Jauhiainen M, Kovanen PT, Leinonen M, Saikku P, Pussinen PJ: Chlamydial and periodontal pathogens induce hepatic inflammation and fatty acid imbalance in apolipoprotein E-deficient mice. Infect Immun 2009, 77(8):3442-3449.

21. Van Oosten M, Rensen PC, Van Amersfoort ES, Van Eck M, Van Dam AM, Breve JJ, Vogel T, Panet A, Van Berkel TJ, Kuiper J: Apolipoprotein E protects against bacterial lipopolysaccharide-induced lethality. A new therapeutic approach to treat gram-negative sepsis. J Biol Chem 2001, 276(12):8820-8824.

22. Törmäkangas L, Alakärppä H, David DB, Leinonen M, Saikku P. Telithromycin treatment of chronic Chlamydia pneumoniae infection in C57BL/6J mice. Antimicrob Agents Chemother 2004, 48(10):3655-3661.

23. Benjamini $Y$, Hochberg $Y$ : Controlling the false discovery rate: a practical and powerful approach to multiple testing. J R Stat Soc B Methodol 1995, 57(1):289-300.

24. Pfaffl MW: A new mathematical model for relative quantification in realtime RT-PCR. Nucleic Acids Res 2001, 29(9):e45.

25. Hara A, Radin NS: Lipid extraction of tissues with a low-toxicity solvent. Anal Biochem 1978, 90(1):420-426.

26. Stoffel W, Chu F, Ahrens EH: Analysis of Long-Chain Fatty Acids by Gasliquid Chromatography. Anal Chem 1959, 31(2):307-308.

27. Mehta NN, McGillicuddy FC, Anderson PD, Hinkle CC, Shah R, Pruscino L, Tabita-Martinez J, Sellers KF, Rickels MR, Reilly MP: Experimental endotoxemia induces adipose inflammation and insulin resistance in humans. Diabetes 2010, 59(1):172-181.

28. Heinecke JW, Li W, Francis GA, Goldstein JA: Tyrosyl radical generated by myeloperoxidase catalyzes the oxidative cross-linking of proteins. J Clin Invest 1993, 91(6):2866-2872.

29. Ward PP, Mendoza-Meneses M, Park PW, Conneely OM: Stimulusdependent impairment of the neutrophil oxidative burst response in lactoferrin-deficient mice. Am J Pathol 2008, 172(4):1019-1029.
30. Pouliot P, Plante I, Raquil MA, Tessier PA, Olivier M: Myeloid-related proteins rapidly modulate macrophage nitric oxide production during innate immune response. J Immunol 2008, 181(5):3595-3601.

31. Jacobsen LC, Sorensen OE, Cowland JB, Borregaard N, Theilgaard-Monch K The secretory leukocyte protease inhibitor (SLPI) and the secondary granule protein lactoferrin are synthesized in myelocytes, colocalize in subcellular fractions of neutrophils, and are coreleased by activated neutrophils. J Leukoc Biol 2008, 83(5):1155-1164.

32. López-Bermejo A, Ortega FJ, Castro A, Ricart W, Fernández-Real J: The alarm secretory leukocyte protease inhibitor increases with progressive metabolic dysfunction. Clin Chim Acta 2011, 412(11-12):1122-1126.

33. Li M, Fu W, Li XA: Differential fatty acid profile in adipose and nonadipose tissues in obese mice. Int I Clin Exp Med 2010, 3(4):303.

34. Suganami T, Tanimoto-Koyama K, Nishida J, Itoh M, Yuan X, Mizuarai S, Kotani H, Yamaoka S, Miyake K, Aoe S, Kamei Y, Ogawa Y: Role of the Tolllike receptor 4/NF-kappaB pathway in saturated fatty acid-induced inflammatory changes in the interaction between adipocytes and macrophages. Arterioscler Thromb Vasc Biol 2007, 27(1):84-91.

35. Alhusaini S, McGee K, Schisano B, Harte A, McTernan P, Kumar S, Tripathi G: Lipopolysaccharide, high glucose and saturated fatty acids induce endoplasmic reticulum stress in cultured primary human adipocytes: Salicylate alleviates this stress. Biochem Biophys Res Commun 2010, 397(3):472-478.

36. Lee JY, Zhao L, Youn HS, Weatherill AR, Tapping R, Feng L, Lee WH, Fitzgerald KA, Hwang DH: Saturated fatty acid activates but polyunsaturated fatty acid inhibits Toll-like receptor 2 dimerized with Toll-like receptor 6 or 1. J Biol Chem 2004, 279(17):16971-16979.

37. Zu L, He J, Jiang H, Xu C, Pu S, Xu G: Bacterial endotoxin stimulates adipose lipolysis via toll-like receptor 4 and extracellular signal-regulated kinase pathway. J Biol Chem 2009, 284(9):5915-5926.

38. Romano Carratelli C, Mazzola N, Paolillo R, Sorrentino S, Rizzo A: Toll-like receptor-4 (TLR4) mediates human beta-defensin-2 (HBD-2) induction in response to Chlamydia pneumoniae in mononuclear cells. FEMS Immunol Med Microbiol 2009, 57(2):116-124.

39. Meir KS, Leitersdorf E: Atherosclerosis in the apolipoprotein-E-deficient mouse: a decade of progress. Arterioscler Thromb Vasc Biol 2004, 24(6):1006-1014.

40. Huang ZH, Gu D, Mazzone T: Role of adipocyte-derived apoE in modulating adipocyte size, lipid metabolism, and gene expression in vivo. Am J Physiol Endocrinol Metab 2009, 296(5):E1110-E1119.

41. Huang ZH, Minshall RD, Mazzone T: Mechanism for endogenously expressed ApoE modulation of adipocyte very low density lipoprotein metabolism: role in endocytic and lipase-mediated metabolic pathways. J Biol Chem 2009, 284(46):31512-31522.

42. Yang $X$, Schadt EE, Wang S, Wang H, Arnold AP, Ingram-Drake L, Drake TA, Lusis AJ: Tissue-specific expression and regulation of sexually dimorphic genes in mice. Genome Res 2006, 16(8):995-1004.

\section{doi:10.1186/1471-2164-14-709}

Cite this article as: Hyvärinen et al.: The effect of proatherogenic pathogens on adipose tissue transcriptome and fatty acid distribution in apolipoprotein E-deficient mice. BMC Genomics 2013 14:709.

\section{Submit your next manuscript to BioMed Central and take full advantage of:}

- Convenient online submission

- Thorough peer review

- No space constraints or color figure charges

- Immediate publication on acceptance

- Inclusion in PubMed, CAS, Scopus and Google Scholar

- Research which is freely available for redistribution 